\title{
Stratigraphic status of coal horizon in Tatapani-Ramkola Coalfield, Chhattisgarh, India
}

\author{
Archana Tripathi ${ }^{1}$, Vijaya ${ }^{1}$, Srikanta Murthy ${ }^{1, *}$, B Chakarborty ${ }^{2}$ and D K Das ${ }^{2}$ \\ ${ }^{1}$ Birbal Sahni Institute of Palaeobotany, Lucknow, India. \\ ${ }^{2}$ Geological Survey of India, Kolkata, India. \\ *Corresponding author.e-mail: srikanta_murthy22@rediffmail.com
}

\begin{abstract}
The palynostratigraphic data given here are based on the explored borecores (TRBD-2, TRBD-3 and TROD-1), by Geological Survey of India. The Permian strata worked-out is about $1174.00 \mathrm{~m}$ thick and comprises from base to top - Talchir, Barakar and Barren Measures formations. The palynological content enables delimitation of five palynological assemblages. (i) Scheuringipollenites barakarensis, (ii) Faunipollenites varius, (iii) Gondisporites raniganjensis, (iv) Densipollenites magnicorpus, and (v) Krempipollenites indicus in ascending order from the subsuface rock strata. The lithologically identified strata Talchir Formation in borecores TRBD-2 and TRBD-3 is palynologically dated late Early Permian in having the Scheuringipollenites barakarensis and the Faunipollenites varius palynozones. Subsequently, the part of Barakar strata in these borecores corroborates with Barakar Formation. In borecore TRBD-3, the Barren Measures rocks do not match with the palynological dates, and are affiliated with the palynoflora of the Raniganj Formation. In TROD-1, the strata identified as Barakar Formation is dated Late Permian in having Gondisporites ranigangensis Palynozone; while that of Barren Measures Formation is palynologically dated Early Triassic having Krempipollenites indicus Palynozone. The palynology has helped in the precise dating of the Lower Gondwana succession of Odari and Bartikhurd blocks in Tatapani-Ramkola Coalfield of South Rewa Gondwana Basin.
\end{abstract}

\section{Introduction}

The present study focuses on the palynostratigraphy of coal-bearing sedimentary rocks in the Tatapani-Ramkola Coalfield, Chattisgarh, India. The coal-bearing Lower Gondwana rocks are exposed along the peripheral region. The Gondwana sediments are represented by variable thickness of different formations starting from Talchir Formation at the base to Supra Panchet Formation at the highest stratigraphic level (Raja Rao 1983). Very little palaeobotanical work has been carried out in this area (Bose et al 1977; Srivastava et al 1997). The biostratigraphic knowledge is very limited (Srivastava and Kar 2001). Henceforth, the primary objective of the present study is to buildup the palynozonation to provide biostratigraphy in the study area.

\section{General geology}

The east-west trending Tatapani-Ramkola Coalfield is the eastern member of the south Rewa Basin of the Son-Mahanadi Valley Master Basin. In this coalfield, coal bearing Lower Gondwana sediments occurring in the north and east (Tatapani

Keywords. Talchir Formation; Barakar Formation; Barren Measures; Bartikhurd block; Tatapani-Ramkola Coalfield. 
sector) are separated from those cropping-out in the south (Ramkola sector) by vast stretches of area occupied by the formational units of Upper Gondwana Group. The coal bearing Lower Gondwana sediments disposed in an arcuate pattern occur along the northern part of the coalfield and take a southerly turn from Pipra hill in the east and finally terminate against the east-west trending border fault (Tatapani fault?) passing north of Tatapani village. In the northern side, the Lower Gondwana rocks unconformably overlie Surguja Crystalline Complex in the east, while in west the boundary between the two is faulted. This forms the Tatapani sector (figure 1).

In the southern part, the coal bearing Lower Gondwanas are exposed in the east-west stretch extending from Duba in the east to Ramkola in the west, and are juxtaposed against Surguja Crystalline Complex along EW trending southern boundary fault. This southern strip of Lower Gondwana rocks comprises the Ramkola sector.

Odari block in the south-central part of the Tatapani-Ramkola Coalfield contains coal bearing Barakar Formation under the cover of Barren Measures. However, in Bartikhurd block occurring west of Odari block, the coal bearing Barakar Formation is intersected under Raniganj Formation and Barren Measures (table 1).
The generalized stratigraphic sequence in Tatapani-Ramkola Basin is given in table 1.

\section{Materials and method}

Total depth in the three borecores is approximately $38.45 \mathrm{~m}$ in TRBD-2, $496.00 \mathrm{~m}$ in TRBD3 and $649.40 \mathrm{~m}$ depth in TROD-1. Sediments are processed by standard maceration technique, i.e., $50 \mathrm{gm}$ of sediments taken and crushed, were first treated with $40 \%$ hydrofluoric acid for $3-4$ days (to remove silica material), and then followed by Nitric acid for 5 days (digestion of humic matter). Further to this, it is treated with $10 \%$ potassium hydroxide to release the humus. The maceral were mounted in Polyvinyl alcohol and Canada balsam. Five slides from each sample were prepared and pollen-spores were observed under the binocular microscope.

\section{Study material}

For present palynological study, in all, the samples were collected from three borecores. The details are given on the next page.

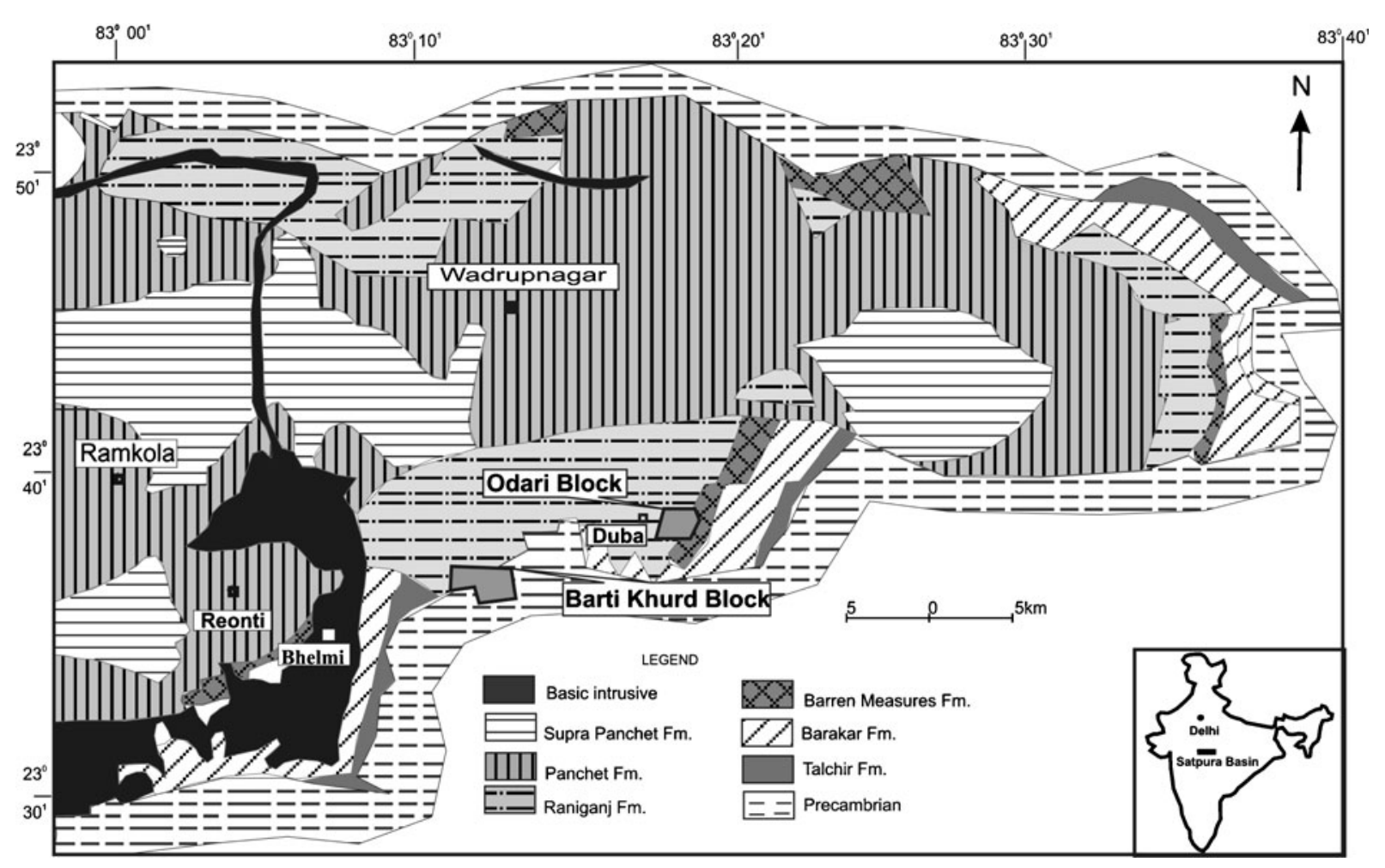

Figure 1. Tatapani-Ramkola Coalfield showing the trap blocks - Bartikhurd and Odari, from where the bore core material is obtained for the present study. 
Table 1. General stratigraphic succession of Tatapani-Ramkola Coalfield, Chhattisgarh.

\begin{tabular}{|c|c|c|c|}
\hline Age & Formation & Thickness & Lithology \\
\hline Recent & Alluvium & & Soil, sand, clay \\
\hline $\begin{array}{l}\text { Late Cretaceous } \\
\text { to Palaeocene }\end{array}$ & Basic intrusive & $100 \mathrm{~m}$ & Dolerite \\
\hline $\begin{array}{l}\text { Early Jurassic to } \\
\text { Late Triassic }\end{array}$ & Supra-Panchet & $200 \mathrm{~m}+$ & $\begin{array}{l}\text { Dirty white to brick red, loose, medium- to coarse-grained } \\
\text { arenites with ferruginous matrix and with profuse rounded, } \\
\text { flat, medium-sized pebbles of quartz; thin oligomictic } \\
\text { conglomerate. }\end{array}$ \\
\hline & Low an & ar unconfor & $\bar{t}$ \\
\hline \multirow[t]{3}{*}{$\begin{array}{l}\text { Middle to Early } \\
\text { Triassic }\end{array}$} & Panchet & & $\begin{array}{l}\text { Mostly massive to cross-bedded sandstone, dirty white } \\
\text { to red, and medium- to coarse-grained arenites with }\end{array}$ \\
\hline & i) Upper & $550 \mathrm{~m}+$ & $\begin{array}{l}\text { ferruginous matrix and occasional carbonate cement, } \\
\text { rare oligomictic conglomerate and occasional red clay. }\end{array}$ \\
\hline & ii) Lower & $250 \mathrm{~m}+$ & $\begin{array}{l}\text { Dirty white to red, greenish white and mottled, medium- } \\
\text { to coarse-grained subarkose to arenite with or without } \\
\text { ferruginous matrix variegated clays. }\end{array}$ \\
\hline Late Permian & Raniganj & $420 \mathrm{~m}+$ & $\begin{array}{l}\text { Fine- to medium-grained, micaceous feldspathic sandstone, } \\
\text { dark grey to grey shale, intercalation of shale and } \\
\text { sandstone, siltstone, impersistent coal seams. }\end{array}$ \\
\hline Late Permian & Barren Measures & $300 \mathrm{~m}+$ & $\begin{array}{l}\text { Predominantly grey to black shale (at places carbonaceous) } \\
\text { with minor fine-grained sandstone (occasionally greenish) } \\
\text { and siltstone with very thin coal bands. }\end{array}$ \\
\hline Early Permian & Barakar & $468 \mathrm{~m}+$ & $\begin{array}{l}\text { Conglomerate very coarse to pebbly sandstone, fine- to } \\
\text { medium-grained sub-arkose, siltstone, vintercalation of } \\
\text { shale and sandstone, carbonaceous shale and regional } \\
\text { and local coal seams. }\end{array}$ \\
\hline $\begin{array}{l}\text { Early Permian to } \\
\text { Late carboniferous }\end{array}$ & Talchir & $160 \mathrm{~m}+$ & $\begin{array}{l}\text { Diamictite, coarse- to fine-grained sub-arkose to arenite } \\
\text { with conglomerate lenses, siltstones, variegated and } \\
\text { green shale, limestone and very rare chart bands. }\end{array}$ \\
\hline Precambrian & $\begin{array}{l}\text { Surguja, } \\
\text { crystalline, } \\
\text { complex }\end{array}$ & & $\begin{array}{l}\text { Granites, gneisses, quartzite, mica-schist, phyllites, } \\
\text { amphibolites. }\end{array}$ \\
\hline
\end{tabular}

\subsection{Bartikhurd Block}

Borecore - TRBD-2 (table 2)

Depth - 315.00-353.45 m

Formational contact - Barakar/Talchir formations at $329.81 \mathrm{~m}$

No. of samples -17

Productive samples -8

Borecore - TRBD-3 (table 3)

Depth - 19.00-515.20 m

Formational contact - Barakar/Talchir formations at $496.60 \mathrm{~m}$; Barren Measures/Barakar at $211.86 \mathrm{~m}$ No. of samples -110

Productive samples -72

\subsection{Odari Block}

Borecore - TROD-1 (table 4)
Depth - 5.66-645.15 m

Formational contact - Barren Measures/Barakar formations at $443.50 \mathrm{~m}$

No. of samples - 144

Productive samples - 108

\section{Palynological observations}

The observations are based on total of ca $1174.10 \mathrm{~m}$ thick strata from all the three borecores. The palynoflora recovered in the productive samples consists of moderately well preserved spores and pollen (Plates 1, 2; tables 2, 3 and 4) derived from the terrestrial material with some acritarchs. The compositional variations among spores and pollens are considered for the identification of assemblages. The presently identified Assemblages I to VI in three borecores are compared with the scheme 
Table 2. Details of lithofacies and the recovery of yield of spore-pollen and Taphonomic remains at different depths in Borehole TRBD-2, Tatapani-Ramkola Coalfield, Chhattisgarh.

\begin{tabular}{|c|c|c|}
\hline Depth (m) & Lithology & Remarks \\
\hline \multicolumn{3}{|c|}{ Contact Talchir/Barakar } \\
\hline 315.60 & Dark grey shale & $\begin{array}{l}\text { Preservation good, spore-pollen rich, organic } \\
\text { matter common to rich }\end{array}$ \\
\hline 316.46 & Grey silty shale & $\begin{array}{l}\text { Organic plant tissues and plant matter variedly } \\
\text { represented }\end{array}$ \\
\hline 337.30 & Boulder+sandstone matrix & $\begin{array}{l}\text { Preservation bad-fair, spore-pollen rare, organic } \\
\text { matter rare-common }\end{array}$ \\
\hline 338.15 & Fine grained sandstone & \multirow{3}{*}{$\begin{array}{l}\text { Organic plant tissues and plant matter variedly } \\
\text { represented }\end{array}$} \\
\hline 339.00 & Fine grained sandstone & \\
\hline 343.25 & Matrix sandstone + clast & \\
\hline 328.00 & Coal & $\begin{array}{l}\text { Preservation bad-fair, spore-pollen rare, organic } \\
\text { matter rich }\end{array}$ \\
\hline 328.50 & Silty sandstone & $\begin{array}{l}\text { Preservation bad, spore-pollen rare, wood } \\
\text { pieces rich }\end{array}$ \\
\hline 329.40 & Cross coal & $\begin{array}{l}\text { Organic plant tissues and plant matter variedly } \\
\text { represented }\end{array}$ \\
\hline $\begin{array}{l}330.10 \\
332.35\end{array}$ & $\begin{array}{l}\text { Fine grained sandstone } \\
\text { Fine grained matrix } \\
\text { sandstone }\end{array}$ & $\begin{array}{l}\text { Preservation fair, spore-pollen rare-common, } \\
\text { unidentifiable matter rare-common }\end{array}$ \\
\hline 344.50 & Finegrainedsandstone & \multirow{3}{*}{$\begin{array}{l}\text { Organic plant tissues and plant matter is variedly } \\
\text { represented }\end{array}$} \\
\hline 347.65 & Finegrainedsandstone & \\
\hline 348.30 & Finegrainedsandstone & \\
\hline 352.25 & Sandstone matrix & $\begin{array}{l}\text { Preservation fair, spore-pollen rare-common, } \\
\text { unidentifiable matter rare-common }\end{array}$ \\
\hline 355.70 & Sandstone matrix & $\begin{array}{l}\text { Organic plant tissues and plant matter } \\
\text { variedly represented }\end{array}$ \\
\hline 356.45 & Sandstone matrix & $\begin{array}{l}\text { Preservation fair, spore-pollen rare-common, } \\
\text { unidentifiable matter rare-common }\end{array}$ \\
\hline
\end{tabular}

proposed by Tiwari and Tripathi (1992). The vertical ranges of index species are considered as given by Vijaya et al (2001). The below given details of assemblages are borecore wise.

\subsection{Borecore-TRBD-2 (approx. $38.45 \mathrm{~m}$ )}

In the total run from 315.00-353.45 m depth, only one assemblage is identified.

\subsubsection{Assemblage-I (table 6)}

Depth: 315.00-337.30 m, 352.25-356.45 m Dominant: Parasaccites, Scheuringipollenites Associated taxa: Dentatispora, Callumispora, Microbaculispora, Microfoveolatispora, Cyclogranisporites, Cyclobaculisporites, Verrucosisporites, Acanthotriletes, Leiotriletes, Jayantisporites, Laevigatosporites, Densipollenites, Faunipollenites, Circumstriatites, Striatopodocarpites,
Crescentipollenites, Verticipollenites and Schizopollis (table 5).

Index species: Indotriradites sparsus, Rhizomaspora indica, Striatites communis, Verticipollenites gibbosus and Densipollenites indicus.

Palynodating: The assemblage is rich in having simple as well as zonate trilete spores, their representation increases in the up-section. The composition of this assemblage is similar to that known from the lower part of the Barakar Formation in the Damodar Basin, in having abundance of Parasaccites and Scheuringipollenites-Faunipollenites along with the above-mentioned index species. Assemblage-I is placed in Scheuringipollenites barakarensis assemblage zone of Tiwari and Tripathi (1992). It is dated as late Early Permian.

\subsection{Borecore-TRBD-3 (approx. $496.00 \mathrm{~m}$ )}

In the total run from 19.00-515.20 m depth, three assemblage zones are identified. 
Table 3. Details of lithofacies and the recovery of spore-pollen and other associated plant-remains, at different depths in Borehole TRBD-3, Tatapani-Ramkola Coalfield, Chhattisgarh.

\begin{tabular}{|c|c|c|}
\hline Depth $(\mathrm{m})$ & Lithology & Remarks \\
\hline 19.00 & Laminated shale & Preservation bad, spore-pollen rare, organic matter rich \\
\hline 20.30 & Laminated shale & Preservation good, spore-pollen rich, organic matter rich \\
\hline 22.00 & Laminated shale & Organic plant tissues and plant matter variedly represented \\
\hline 26.30 & Silty shale & $\begin{array}{l}\text { Preservation fair, spore-pollen rich, organic plant tissue } \\
\text { material bad-fair }\end{array}$ \\
\hline 29.60 & Silty shale & \multirow{5}{*}{$\begin{array}{l}\text { Organic plant tissues and plant matter variedly } \\
\text { represented }\end{array}$} \\
\hline 32.70 & Micaceous grey shale & \\
\hline 35.80 & Silty shale & \\
\hline 38.70 & Dark grey shale & \\
\hline 44.40 & Dark grey shale & \\
\hline 48.20 & Grey laminated silty sandstone & Preservation fair, spore-pollen rich, other plant tissue common \\
\hline $\begin{array}{l}52.00 \\
54.80\end{array}$ & $\left.\begin{array}{l}\text { Grey shale } \\
\text { Grey micaceous shale }\end{array}\right\}$ & Organic matter and other plant tissue variedly represented \\
\hline 57.50 & Grey shale & Preservation fair, spore-pollen rich, other plant tissue rare-common \\
\hline $\begin{array}{l}61.00 \\
63.70\end{array}$ & $\begin{array}{l}\text { Grey micaceous shale } \\
\text { Grey micaceous shale }\end{array}$ & Organic plant tissues and plant matter variedly represented \\
\hline 69.90 & Dark grey shale & Preservation good, spore-pollen rich, organic matter common \\
\hline 73.00 & Laminated silty shale & \multirow{3}{*}{ Organic matter and plant tissue variedly represented } \\
\hline 77.55 & Micaceous grey shale & \\
\hline 80.40 & Dark grey shale & \\
\hline 84.50 & Coal & Preservation bad, spore-pollen rare, other plant tissue rich \\
\hline 88.30 & Grey silty sandstone & \multirow{2}{*}{ Organic matter and other plant tissue variedly represented } \\
\hline 92.10 & Dark grey micaceous shale & \\
\hline 94.45 & Dark grey micaceous shale & Preservation bad, spore-pollen rare, other plant material rich \\
\hline 101.00 & Dark grey shale & Organic matter and plant tissue variedly represented \\
\hline 106.70 & Dark grey shale & Preservation fair, spore-pollen common, other plant tissue common \\
\hline 110.00 & Silt+sandstone cross & Organic matter and plant tissue variedly represented \\
\hline 113.10 & Laminated dark grey shale & Preservation bad, spore-pollen rare, organic matter rich \\
\hline 116.00 & Shale & \multirow{2}{*}{ Organic matter and plant tissue variedly represented } \\
\hline 118.40 & Shale+sandstone $\int$ & \\
\hline 123.20 & Grey shale cross laminated & Preservation good, spore-pollen rich, other plant tissue common \\
\hline 129.40 & Grey shale micaceous & \multirow{5}{*}{ Organic matter and other plant tissue variedly represented } \\
\hline 133.40 & Carbonaceous shale & \\
\hline 137.35 & Shale+sandstone & \\
\hline 141.80 & Black shale micaceous & \\
\hline 144.90 & Black shale micaceous & \\
\hline 150.00 & Coal band in shale & Preservation fair, spore-pollen common, other plant tissue rich \\
\hline 154.20 & Dark shale $\}$ & \multirow{2}{*}{ Organic matter and other plant tissue variedly represented } \\
\hline 157.30 & Grey shale & \\
\hline 160.40 & Black shale & \multirow[t]{5}{*}{ Preservation good, spore-pollen rich, other plant tissue common } \\
\hline 166.60 & Black shale & \\
\hline 172.10 & Black shale & \\
\hline 176.40 & Grey silt shale & \\
\hline 179.50 & Grey silt shale & \\
\hline 182.00 & Black shale & \multirow[t]{5}{*}{ Organic matter and plant tissue variedly represented } \\
\hline 188.20 & Black shale & \\
\hline 193.75 & Black shale & \\
\hline 197.30 & Black shale & \\
\hline 201.45 & Black shale & \\
\hline 207.35 & Black shale & Preservation good, spore-pollen rich, other plant tissue common \\
\hline
\end{tabular}


Table 3. (Continued.)

\begin{tabular}{|c|c|c|}
\hline Depth $(\mathrm{m})$ & Lithology & Remarks \\
\hline 210.45 & Siltstone & \multirow{4}{*}{ Organic matter and plant tissue variedly represented } \\
\hline 216.65 & Siltstone & \\
\hline 219.75 & Hard compact black shale & \\
\hline 222.85 & Grey shale & \\
\hline 225.95 & Black shale & $\begin{array}{l}\text { Preservation bad-fair, spore-pollen rich but broken, } \\
\text { organic matter rare }\end{array}$ \\
\hline 230.40 & Black shale & \multirow{4}{*}{ Organic matter and plant tissue variedly represented } \\
\hline 235.25 & Shale & \\
\hline 238.50 & Black shale & \\
\hline 244.70 & Black shale & \\
\hline 247.80 & Grey shale & Preservation bad, spore-pollen rare, organic matter rich \\
\hline 253.15 & Grey shale & \multirow{3}{*}{ Organic matter and plant tissue variedly represented } \\
\hline 256.25 & Grey shale & \\
\hline 260.00 & Grey shale & \\
\hline 262.40 & Carbonaceous shale & $\begin{array}{l}\text { Preservation fair, spore-pollen rare, other plant } \\
\text { tissue rich }\end{array}$ \\
\hline 266.30 & Coal & \multirow{4}{*}{ Organic matter and plant tissue variedly represented } \\
\hline 270.70 & Grey shale & \\
\hline $271.37-272.74$ & Coal & \\
\hline 273.20 & Siltstone & \\
\hline 283.10 & Grey shale & $\begin{array}{l}\text { Preservation good, spore-pollen rich, other plant } \\
\text { tissue rare }\end{array}$ \\
\hline 288.30 & Shale & \multirow{6}{*}{ Organic matter and plant tissue variedly represented } \\
\hline $288.48-289.52$ & Coal & \\
\hline 291.10 & Black shale & \\
\hline 297.45 & Grey shale & \\
\hline 300.40 & Silt shale & \\
\hline $301.09-302.65$ & Coal & \\
\hline 322.10 & Black shale & $\begin{array}{l}\text { Preservation good, spore-pollen common, organic } \\
\text { matter and wood rich }\end{array}$ \\
\hline 331.75 & Fine grained sandstone & \multirow{5}{*}{ Organic matter and plant tissue variedly represented } \\
\hline 361.00 & Dark grey micaceous shale & \\
\hline 368.90 & Thin coal in sandstone & \\
\hline 374.30 & Thin coal in sandstone & \\
\hline 384.50 & Siltstone & \\
\hline 393.25 & Coal & $\begin{array}{l}\text { Preservation bad, spore-pollen rare, organic matter } \\
\text { common, blackish splintry wood rich }\end{array}$ \\
\hline 401.45 & Shale+sandstone & \multirow{2}{*}{$\begin{array}{l}\text { Organic plant tissues and plant matter variedly } \\
\text { represented }\end{array}$} \\
\hline 403.30 & Coal $40 \mathrm{~cm}$ & \\
\hline 41420 & Gedium sing & \multirow{2}{*}{$\begin{array}{l}\text { Preservation bad, spore-pollen rare, organic matter } \\
\text { common }\end{array}$} \\
\hline $\begin{array}{l}414.20 \\
415.85\end{array}$ & $\begin{array}{l}\text { Medium fine grained sandstone } \\
\text { Medium fine grained sandstone }\end{array}$ & \\
\hline 424.40 & Cross beded very fine grained sandstone & \multirow{3}{*}{ Organic matter and plant tissue variedly represented } \\
\hline 434.96 & Cross laminated shale+sandstone & \\
\hline 436.20 & Cross laminated fine grained sandstone & \\
\hline 438.80 & Coal band $35 \mathrm{~cm}$ & $\begin{array}{l}\text { Preservation bad, spore-pollen rich, organic matter } \\
\text { in lumps }\end{array}$ \\
\hline 442.40 & Cross laminated & \multirow{3}{*}{$\begin{array}{l}\text { Organic plant tissues and plant matter variedly } \\
\text { represented }\end{array}$} \\
\hline 450.55 & Dark grey shale & \\
\hline 452.24 & Dark grey shale & \\
\hline 462.69 & Black shale & $\begin{array}{l}\text { Preservation bad, spore-pollen very rare, blackish } \\
\text { unidentified matter rich }\end{array}$ \\
\hline
\end{tabular}


Table 3. (Continued.)

\begin{tabular}{|c|c|c|}
\hline Depth $(\mathrm{m})$ & Lithology & Remarks \\
\hline 463.50 & Laminated fine grained sandstone & \multirow{2}{*}{ Organic plant tissues and plant matter variedly represented } \\
\hline 466.00 & Laminated fine grained sandstone & \\
\hline 479.60 & Coal & $\begin{array}{l}\text { Preservation bad, spore-pollen very rare, rich in splintary } \\
\text { wood matter }\end{array}$ \\
\hline 483.38 & Grey fine grained sandstone & \multirow{6}{*}{ Preservation fair, spore-pollen common, organic plant tissue rich } \\
\hline 484.51 & Grey shale & \\
\hline 486.10 & Grey shale & \\
\hline 489.40 & Thin coal band & \\
\hline 492.50 & Coal band $15 \mathrm{~cm}$ & \\
\hline 495.50 & Coarse grained sandstone + coal & \\
\hline 496.60 & Contact Barakar Talchir & \multirow{4}{*}{ Organic plant tissues and plant matter variedly represented } \\
\hline 496.96 & Green fine grained sandstone+shale & \\
\hline 497.50 & Fine grained sandstone & \\
\hline 501.60 & Green+grey silt stone & \\
\hline 507.80 & Boulder bed matrix & Preservation bad, spore-pollen rare, organic matter common \\
\hline 510.50 & Very fine grained green sandstone & Organic matter and plant tissue variedly represented \\
\hline 511.55 & Calcareous shale in mg. & Preservation bad, spore-pollen rare, organic matter rare \\
\hline 512.15 & Medium sandstone & \multirow{3}{*}{ Organic matter and plant tissue variedly represented } \\
\hline 513.25 & Fine grained sandstone & \\
\hline 515.20 & Medium sandstone & \\
\hline
\end{tabular}

\subsubsection{Assemblage-II (table 7)}

Depth: 393.25-511.55 m

Dominant: Striatopodocarpites, Faunipollenites, Scheuringipollenites

Associated taxa: Cyclogranisporites, Microbaculispora, Horriditriletes, Callumispora, Indotriradites, Dentatispora, Caheniasaccites, Parasaccites, Plicatipollenites, Densipollenites, Sahnites, Platysaccus, Scheuringipollenites, Striatites, Crescentipollenites, Verticipollenites, Schizopollis, Striasulcites, Tiwariasporis, Laevigatosporites, Weylandites and Ginkgocycadophytes (table 5).

Index species: Didecitriletes horridus, Densipollenites densus, Horriditriletes curvibaculosus, Cyclobaculisporites gondwanensis, Verticipollenites crassus, Striatopodocarpites ovatus.

Palynodating: The composition of Assemblage-II is very similar to the palynoflora from the upper part of the Barakar Formation in the Damodar Basin, in having abundance of Faunipollenites and Scheuringipollenites along with above-mentioned index species. It is placed in the Faunipollenites varius assemblage zone of Tiwari and Tripathi (1992), and is dated late Early Permian in age.

\subsubsection{Assemblage-III (table 7)}

Depth: 57.30-283.10 m

Dominant: Striatopodocarpites
Associated taxa: Cyclogranisporites, Cyclobaculisporites, Microbaculispora, Horriditriletes, Brevitriletes, Callumispora, Laevigatosporites, Thymospora, Parasaccites, Striamonosaccites, Barakarites, Scheuringipollenites, Sahnites, Vestigisporites, Platysaccus, Faunipollenites, Striatites, Crescentipollenites, Verticipollenites, Distriatites,Schizopollis, Striasulcites, Primuspollenites, Guttulapollenites, Densipollenites, Weylandites, Gondisporites and Welwitsciapites.

Acritarch: Leiosphaeridia and Quadrisporites (table 5).

Index species: Gondisporites reticulates, Distriomonosaccites ovalis, Distriatites bilateris, Verticipollenites oblongus.

Palynodating: In Assemblage-III, variety of trilete spores continue from the older Assemblages I and II, but do not attain high frequency. This composition is very similar to the known palynoflora from lower part of the Raniganj Formation in Damodar Basin and having an abundance of Striatopodocarpites, Funipollenites and Crescentipollenites. Hence, it is placed in the Gondisporites raniganjensis assemblage zone of Tiwari and Tripathi (1992), and dated Late Permian in age. The presence of acritarch is noteworthy.

\subsubsection{Assemblage-IV (table 7)}

Depth: $19.00-54.80 \mathrm{~m}$

Dominant: Densipollenites 
Table 4. Details of lithofacies and the recovery of spore-pollen and other associated remarks at different depths in Borehole TROD-1, Tatapani-Ramkola Coalfield, Chhattisgarh.

\begin{tabular}{|c|c|c|}
\hline Depth $(\mathrm{m})$ & Lithology & Remarks \\
\hline 5.66 & Buff silt sandstone ) & Unproductive \\
\hline 7.85 & Brownish clay & Organic plant tissues and plant matter variedly \\
\hline 9.70 & Brownish clay & represented \\
\hline 10.00 & Brownish clay & $\begin{array}{l}\text { Preservation fair, mixed black or yellow, organic } \\
\text { matter poor, not much }\end{array}$ \\
\hline 10.60 & Mudstone & $\begin{array}{l}\text { Preservation fair, mixed black or yellow, organic } \\
\text { matter poor, not much }\end{array}$ \\
\hline 11.65 & Grey mudstone & $\begin{array}{l}\text { Preservation fair, mixed black or yellow, organic } \\
\text { matter poor, not much }\end{array}$ \\
\hline 11.75 & Grey micaceous shale & $\begin{array}{l}\text { Preservation fair, mixed black or yellow, organic } \\
\text { matter poor, not much }\end{array}$ \\
\hline 12.50 & Grey micaceous shale & Preservation fair, plant tissues or wood rare \\
\hline 13.75 & Light grey shale & \\
\hline 14.40 & Grey silt stone & \\
\hline 14.90 & Grey shale & Preservation tair, plant tissues or wood rare \\
\hline 16.80 & Dark grey mica shale & \\
\hline 19.10 & Dark grey mica shale & Organic plant tissues and plant matter variedly \\
\hline 22.00 & Light grey shale & represented \\
\hline 23.60 & Light grey shale & \\
\hline 26.30 & Grey shale+sandstone & Preservation fair, spore-pollen, other plant tissue rich \\
\hline 28.00 & Grey shale+sandstone & Organic matter and plant tissue variedly \\
\hline 31.70 & Grey shale & represented \\
\hline 33.90 & Grey shale & Preservation fair, spore-pollen, other plant tissue rich \\
\hline 37.20 & Medium grained sandstone & Organic matter and plant tissue variedly represented \\
\hline 40.00 & Dark grey shale & Other plant tissue common, preservation fair \\
\hline 43.00 & Dark grey shale & Organic matter and plant tissue variedly represented \\
\hline 46.00 & Dark grey shale & Preservation bad, other plant tissue rare-common \\
\hline 50.40 & Fine grained silt stone & $\begin{array}{l}\text { Preservation fair, spore-pollen, and other plant } \\
\text { tissue common }\end{array}$ \\
\hline 52.10 & Sandy shale & Preservation bad, other plant tissue and wood rare \\
\hline 54.25 & Micaceous sandy shale & Organic matter and plant tissue variedly represented \\
\hline 56.10 & Grey shale & Preservation fair, other plant tissue rich \\
\hline 58.60 & Grey shale & Preservation fair, other plant tissue common \\
\hline 62.25 & Grey micaceous sandstone & Organic matter poor, fair-good, black wood present \\
\hline 63.90 & Grey micaceous sandstone & Preservation bad, other plant tissue rich \\
\hline 65.50 & Shale & Preservation bad, other plant tissue rich \\
\hline 67.15 & Shale & Preservation bad, other plant tissue rich \\
\hline 71.55 & Grey shale & Preservation bad, other plant tissue rich \\
\hline 75.00 & Grey shale & $\begin{array}{l}\text { Very good preservation, other plant } \\
\text { tissue rare-common }\end{array}$ \\
\hline 79.00 & Grey shale & Good preservation, other plant tissue rare--common \\
\hline 84.60 & Grey shale & Fair preservation, other plant tissue rare-common \\
\hline 86.55 & Silty sandstone & Preservation bad, organic matter rare \\
\hline 91.50 & Grey shale & Good preservation, other plant tissue rare-common \\
\hline 95.30 & Micaceous grey shale & Preservation bad-fair, other plant tissue rich \\
\hline 97.70 & Grey shale in sandstone & Preservation bad-fair, other plant tissue rich \\
\hline 100.60 & Grey shale & Preservation bad-fair, other plant tissue rich \\
\hline 103.80 & Grey shale & Other plant tissue common \\
\hline 107.90 & Fine-grained silty shale & Good preservation, other plant tissue common \\
\hline 110.20 & Dark grey shale & Preservation fair, other plant tissue rich \\
\hline 113.90 & Dark grey shale & Preservation bad, other plant tissue rich \\
\hline 118.15 & Dark grey shale & Preservation good, other plant tissue common \\
\hline
\end{tabular}


Table 4. (Continued.)

\begin{tabular}{|c|c|c|}
\hline Depth (m) & Lithology & Remarks \\
\hline 121.80 & Grey shale & Preservation fair, other plant tissue rare-common \\
\hline 125.05 & Grey shale & Preservation fair, other plant tissue rare-common \\
\hline 129.35 & Grey shale & Preservation fair, other plant tissue rare-common \\
\hline 131.90 & Grey shale & Preservation bad, other plant tissue rare-common \\
\hline 136.00 & Grey shale & Preservation good, other plant tissue rare-common \\
\hline 139.00 & Grey shale & Preservation good, other plant tissue rare-common \\
\hline 142.60 & Grey shale & Preservation good, other plant tissue rare-common \\
\hline 146.00 & Grey shale & Preservation good, other plant tissue rare \\
\hline 148.35 & Sandy grey shale & Preservation good, other plant tissue rare-common \\
\hline 153.00 & Sandy grey shale & Preservation good, other plant tissue rare \\
\hline 156.45 & Sandy grey shale & Preservation bad, other plant tissue rare-common \\
\hline 162.50 & Sandy grey shale & Preservation fair, other plant tissue rich \\
\hline 168.75 & Sandy grey shale & Preservation good, other plant tissue rare-common \\
\hline 171.25 & Sandy grey shale & Preservation fair, other plant tissue rare-common \\
\hline 173.80 & Grey shale & Preservation fair, other plant tissue rich \\
\hline 176.95 & Grey shale & Preservation bad, other plant tissue rich \\
\hline 179.80 & Brown silt stone & Preservation fair, black wood common \\
\hline 181.15 & Grey shale & Preservation fair-good, other plant tissue rich \\
\hline 186.55 & Grey fine grained sandstone & Preservation good, other plant tissue rare-common \\
\hline 189.75 & Silt+sandstone & $\begin{array}{l}\text { Preservation fair, other plant tissue common, } \\
\text { light colour, black wood present }\end{array}$ \\
\hline 195.85 & Grey shale in sandstone & $\begin{array}{l}\text { Preservation fair, other plant tissue common, } \\
\text { light colour, black wood present }\end{array}$ \\
\hline 198.85 & Grey shale & Preservation bad, other plant tissue rich \\
\hline 208.00 & Grey shale & Preservation bad, other plant tissue rich \\
\hline 212.55 & Grey shale & Preservation bad, other plant tissue rich \\
\hline 219.30 & Grey shale & Other plant tissue rare-common, light colour \\
\hline 225.50 & Grey shale & $\begin{array}{l}\text { Other plant tissue rich, light yellow, preservation } \\
\text { fair }\end{array}$ \\
\hline 231.10 & Grey shale & Other plant tissue common, fair-good \\
\hline 235.95 & Grey shale & Preservation good, other plant tissue rich \\
\hline 240.70 & Grey shale & Other plant tissue and big wood pieces common \\
\hline 246.80 & Grey shale & Other plant tissue common, light colour \\
\hline 252.50 & Grey shale & Preservation bad, other plant tissue common \\
\hline 258.50 & Dark grey shale & \\
\hline 264.70 & Dark grey shale & Organic matter and plant tissue variedly \\
\hline 273.95 & Dark grey shale & represented \\
\hline 280.05 & Dark grey shale & \\
\hline 285.50 & Dark grey shale & Preservation fair, other plant tissue rich \\
\hline 290.45 & Grey sandstone +shale & $\begin{array}{l}\text { Organic matter and plant tissue variedly } \\
\text { represented }\end{array}$ \\
\hline 293.45 & Grey sandstone+shale & Preservation fair, other plant tissue rich \\
\hline 299.50 & Grey sandstone+shale & Organic matter and plant tissue variedly \\
\hline 308.55 & Grey sandstone+shale & represented \\
\hline 314.40 & Fine-grained grey sandstone & Preservation fair, other plant tissue common \\
\hline 320.66 & Intercalation sandstone+shale & $\begin{array}{l}\text { Organic matter and plant tissue variedly } \\
\text { represented }\end{array}$ \\
\hline 326.00 & Intercalation sandstone+shale & Preservation bad, other plant tissue rich \\
\hline 332.50 & Intercalation sandstone+shale & $\begin{array}{l}\text { Organic matter and plant tissue variedly } \\
\text { represented }\end{array}$ \\
\hline 339.40 & Intercalation sandstone+shale & Other plant tissue rich, preservation bad-fair \\
\hline 348.10 & Intercalation sandstone+shale & $\begin{array}{l}\text { Organic matter and plant tissue variedly } \\
\text { represented }\end{array}$ \\
\hline
\end{tabular}


Table 4. (Continued.)

\begin{tabular}{|c|c|c|}
\hline Depth (m) & Lithology & Remarks \\
\hline 357.20 & Intercalation sandstone+shale & Other plant tissue rich, preservation bad-fair \\
\hline 364.00 & Intercalation sandstone+shale & $\begin{array}{l}\text { Organic matter and plant tissue variedly } \\
\text { represented }\end{array}$ \\
\hline 371.10 & Shale & Other plant tissue common \\
\hline 377.10 & Shale & $\begin{array}{l}\text { Organic matter and plant tissue variedly } \\
\text { represented }\end{array}$ \\
\hline 382.15 & Dark grey shale & Other plant tissue rare-common \\
\hline 390.30 & Dark grey shale & $\begin{array}{l}\text { Organic matter and plant tissue variedly } \\
\text { represented }\end{array}$ \\
\hline 396.00 & Dark grey shale & Other plant tissue rich, preservation bad-fair \\
\hline 406.50 & Grey shale & $\begin{array}{l}\text { Organic matter and plant tissue variedly } \\
\text { represented }\end{array}$ \\
\hline 409.80 & Grey shale & Other plant tissue rich, bad \\
\hline 422.60 & Micaceous grey shale & Organic matter and plant tissue variedly \\
\hline 428.10 & Pebbles grey shale & represented \\
\hline $429.75-431.40$ & $\left.\begin{array}{l}\text { Carbonaceous shale with } \\
\text { band of shale coal }\end{array}\right\}$ & $\begin{array}{l}\text { Other plant tissue rich, preservation bad, } \\
\text { not clear, black matter attached }\end{array}$ \\
\hline 435.80 & Grey silt shale & $\begin{array}{l}\text { Organic matter and plant tissue variedly } \\
\text { represented }\end{array}$ \\
\hline 442.90 & Grey silty shale & Other plant tissue rich, preservation bad \\
\hline 450.45 & Coaly shale & $\begin{array}{l}\text { Organic matter and plant tissue variedly } \\
\text { represented }\end{array}$ \\
\hline 460.55 & Carbonaceous shale & Preservation bad, other plant tissue common \\
\hline 471.00 & Grey shale & $\begin{array}{l}\text { Organic matter and plant tissue variedly } \\
\text { represented }\end{array}$ \\
\hline 480.00 & Black shale & Other plant tissue rich, yellow colour \\
\hline 486.65 & Black shale & $\begin{array}{l}\text { Organic matter and plant tissue variedly } \\
\text { represented }\end{array}$ \\
\hline 495.70 & Black shale & Other plant tissue rich, yellow colour \\
\hline 499.10 & Black shale & $\begin{array}{l}\text { Organic matter and plant tissue variedly } \\
\text { represented }\end{array}$ \\
\hline 504.00 & Black shale & Other plant tissue rich, preservation bad-fair \\
\hline 508.35 & Intercalation grey shale & $\begin{array}{l}\text { Organic matter and plant tissue variedly } \\
\text { represented }\end{array}$ \\
\hline 513.00 & Grey shale & Rich in black wood pieces, preservation fair \\
\hline 521.45 & Black shale & $\begin{array}{l}\text { Organic matter and plant tissue variedly } \\
\text { represented }\end{array}$ \\
\hline 526.55 & Black shale & $\begin{array}{l}\text { Other plant tissue rich, preservation bad, } \\
\text { light colour }\end{array}$ \\
\hline 531.55 & Grey shale & $\begin{array}{l}\text { Other plant tissue rich, preservation bad, } \\
\text { light colour }\end{array}$ \\
\hline 535.35 & Grey shale & $\begin{array}{l}\text { Other plant tissue rich, preservation bad, } \\
\text { light colour }\end{array}$ \\
\hline 539.00 & Coal band & $\begin{array}{l}\text { Other plant tissue rich, preservation bad, } \\
\text { very light colour }\end{array}$ \\
\hline 545.60 & Black shale & $\begin{array}{l}\text { Organic matter and plant tissue variedly } \\
\text { represented }\end{array}$ \\
\hline 554.55 & Grey shale band in sandstone & $\begin{array}{l}\text { Other plant tissue rare-common, } \\
\text { preservation fair-good }\end{array}$ \\
\hline 562.25 & Coal & $\begin{array}{l}\text { Organic matter and plant tissue variedly } \\
\text { represented }\end{array}$ \\
\hline 568.80 & Dark grey shale & Other plant tissue rich, preservation bad-fair \\
\hline 574.30 & Grey shale & $\begin{array}{l}\text { Organic matter and plant tissue variedly } \\
\text { represented }\end{array}$ \\
\hline
\end{tabular}


Table 4. (Continued.)

\begin{tabular}{|c|c|c|}
\hline Depth $(\mathrm{m})$ & Lithology & Remarks \\
\hline 577.50 & Carbonaceous shale & Other plant tissue rich, preservation bad \\
\hline 586.20 & Carbonaceous shale & Organic matter and plant tissue variedly represented \\
\hline 590.45 & Carbonaceous shale & $\begin{array}{l}\text { Other plant tissue rich, preservation bad, very light } \\
\text { colour }\end{array}$ \\
\hline 594.45 & Siltstone & $\begin{array}{l}\text { Organic plant tissue and plant matter variedly } \\
\text { represented }\end{array}$ \\
\hline 597.90 & Grey shale & Other plant tissue rich, preservation bad-fair \\
\hline 601.40 & Coal & Organic matter and plant tissue variedly represented \\
\hline 608.20 & Grey shale & Other plant tissue rich, light colour \\
\hline 611.50 & Grey shale & Organic matter and plant tissue variedly represented \\
\hline 616.45 & Grey shale in sandstone & Other plant tissue, black wood light, preservation fair \\
\hline 621.15 & Grey shale in sandstone & Organic matter and plant tissue variedly represented \\
\hline 624.80 & Grey shale in sandstone & \\
\hline 629.15 & Grey shale in sandstone & Black organic matter, unidentifiable \\
\hline 631.15 & Grey shale in sandstone & \multirow{2}{*}{ Organic matter and plant tissue variedly represented } \\
\hline 632.90 & Grey shale in sandstone & \\
\hline 636.20 & Grey shale in sandstone & Organic matter rich, preservation fair \\
\hline 640.60 & Grey shale in sandstone & \multirow{2}{*}{ Organic matter and plant tissue variedly represented } \\
\hline 642.10 & Grey shale in sandstone & \\
\hline 645.15 & Coaly shale & Other plant tissue rich, preservation bad-fair \\
\hline
\end{tabular}

Associated taxa: Brevitriletes, Laevigatosporites, Scheuringipollenites, Striatopodocarpites, Faunipollenites, Striatites, Crescentipollenites, Verticipollenites, Distriatites and Vittatina (table 5).

Index species: Lundbladispora brevicula, $L$. microconata, Arcuatipollenites diffusus and Krempipollenites indicus.

Palynodating: The composition of AssemblageIV is similar to that of Assemblage-II. However, presence of taxa Playfordiaspora delineates the stratigraphic placement of this assemblage. It is equivalent to the palynoflora from uppermost Raniganj Formation of Damodar Basin in the dominance of Striatopodocarpites, Densipollenites and Crescentipollenites. It is placed in Densipollenites magnicorpus assemblage zone of Tiwari and Tripathi (1992), and is dated latest Permian in age.

\subsection{Borecore-TROD-1 (approx $649.40 \mathrm{~m}$ )}

In the total run of 5.66-645.15 m, two assemblages are identified.

\subsubsection{Assemblage-V (table 8)}

Depth: 460.50-645.15 m

Dominant: Striatopodocarpites

Associated taxa: Cyclogranisporites, Microbaculispora, Horriditriletes, Brevitriletes, Indotri- radites, Laevigatosporites, Densipollenites, Barakarites, Parasaccites, Plicatipollenites, Potonieisporites, Faunipollenites, Crescentipollenites, Verticipollenites, Distriatites, Striatites, Schizopollis, Scheuringipollenites, Primuspollenites, Arcuatipollenites, Playfordiaspora, Accintisporites and Weylandites (table 5).

Index species: Gondisporites reticulatus, Krempipollenites indicus, Arcuatipollenites diffusus, Gondisporites raniganjensis and Densipollenites magnicorpus.

Palynodating: The overall composition of Assemblage- $\mathrm{V}$ is similar to that known from the upper part of the Raniganj Formation of Damodar Basin having dominance of Striatopodocarpites, Crescentipollenites, Densipollenites along with above-mentioned index species. But these two taxa, Arcuatipollenites pellucidus and Playfordiaspora cancellosa make their appearance at $645.15 \mathrm{~m}$ depth. Therefore, it is placed in the Densipollenites magnicorpus assemblage zone of Tiwari and Tripathi (1992), and is dated as latest Permian in age.

\subsubsection{Assemblage-VI (table 8)}

Depth: $12.50-442.90 \mathrm{~m}$

Dominant: Striatopodocarpites

Associated taxa: Microbaculispora, Horriditriletes, Cyclobaculisporites, Camptotriletes, 

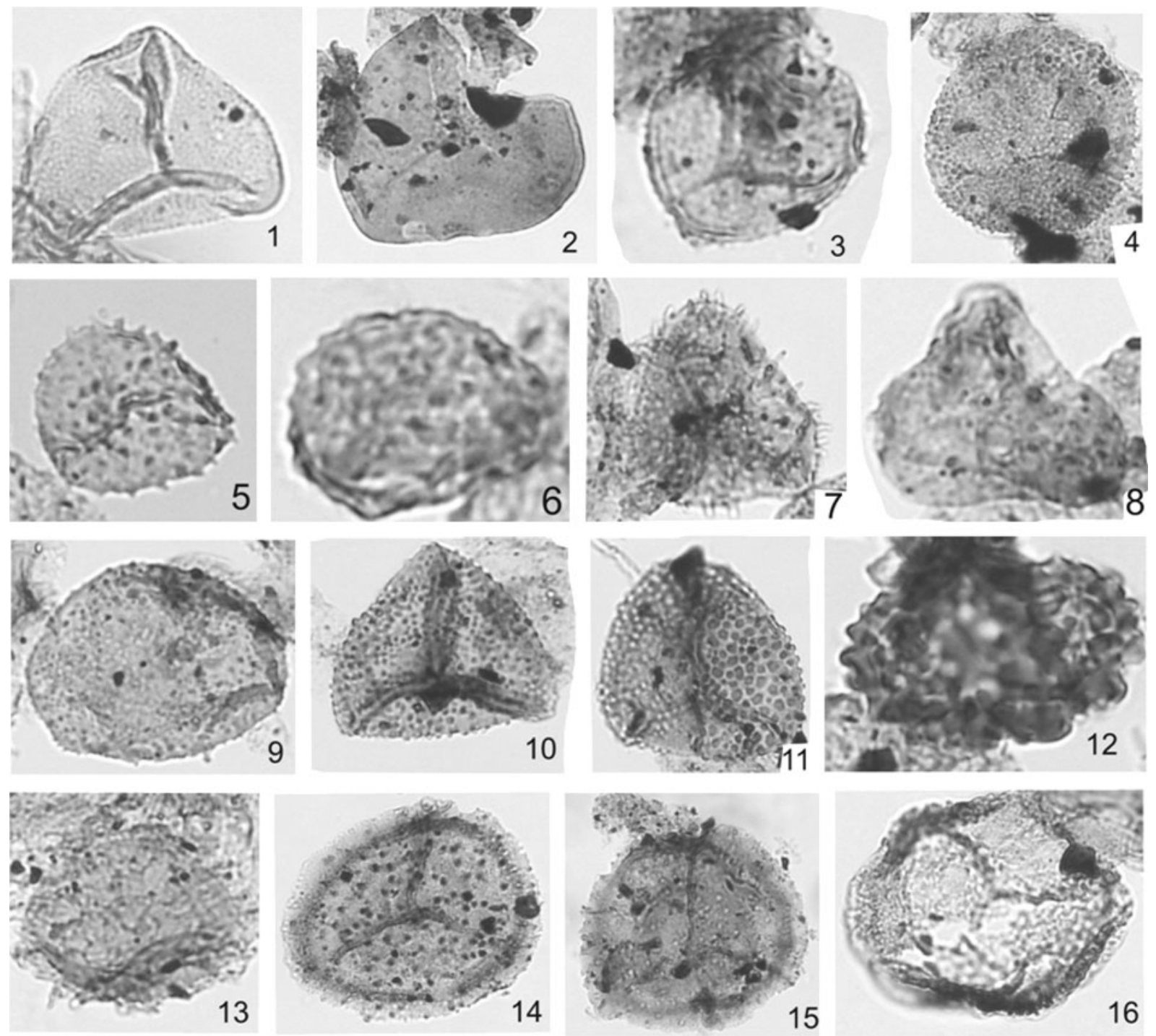

Plate 1. 1. Microfoveolatispora foveolata Tiwari (1965); 2. Microfoveolatispora bokaroensis Tiwari (1965); 3. Cyclogranisporites triletus Kar (1970); 4. Microbaculispora tentulu Tiwari (1965); 5. Brevitriletes unicus Bharadwaj and Srivastava (1969); 6. Thymospora thiessnii Willson and Venkatachala (1963); 7. Horriditriletes curvibaculosus Bharadwaj and Salujha (1964); 8. Horriditriletes sp.; 9. Cyclogranisporites distinctus Kumaran and Maheshwari (1980); 10. Microbaculispora indica (Tiwari) emend. Tiwari and Singh (1981); 11. Microbaculispora barakarensis Tiwari (1965); 12. Verrucosisporites triassicus Bharadwaj and Tiwari (1977); 13. Indotriradites cuspidus (Balme) Bharadwaj and Tiwari (1977); 14. Gondisporites raniganjensis Bharadwaj (1962); 15. Lundbladispora raniganjensis Tiwari and Rana (1981); 16. Ringosporites fossulatus (Balme) Tiwari and Rana (1981).

Osmundacidites, Acanthotriletes, Lophotriletes, Indotriradites, Striamonosaccites, Distriamonosaccites, Krempipollenites, Faunipollenites, Crescentipollenites, Verticipollenites, Distriatites, Striatites, Schizopollis, Striapollenites, Striasulcites, Distriatites, Guttulapollenites, Trabeculisporites, Protoeusaccites, Caytonipollenites, Accintisporites, Alisporites, Weylandites and Tiwariasporis (table 5).

Acritarch: Peltacystia and Quadrisporites.

Index species: Playfordiaspora cancellosa, Satsangisaccites nidpurensis, Plicatisaccus,
Brachysaccus, Minutosaccus, Lundbladispora baculata and Densoisporites sp.

Palynodating: The overall qualitative composition along with index species of this assemblage is akin to the palynoflora recovered from the Lower Triassic succession Panchet Formation of Damodar Basin. Here, the first occurrence of Minutosaccus sp. at $442.90 \mathrm{~m}$, Plicatisaccus sp. and Brachysaccus sp. at $409.80 \mathrm{~m}$ depth is noteworthy. Proliferation of Playfordiaspora cancellosa is noticed at $65.00 \mathrm{~m}$ depth. Considering all these characteristics, the assemblage is placed in the Krempipollenites indicus 

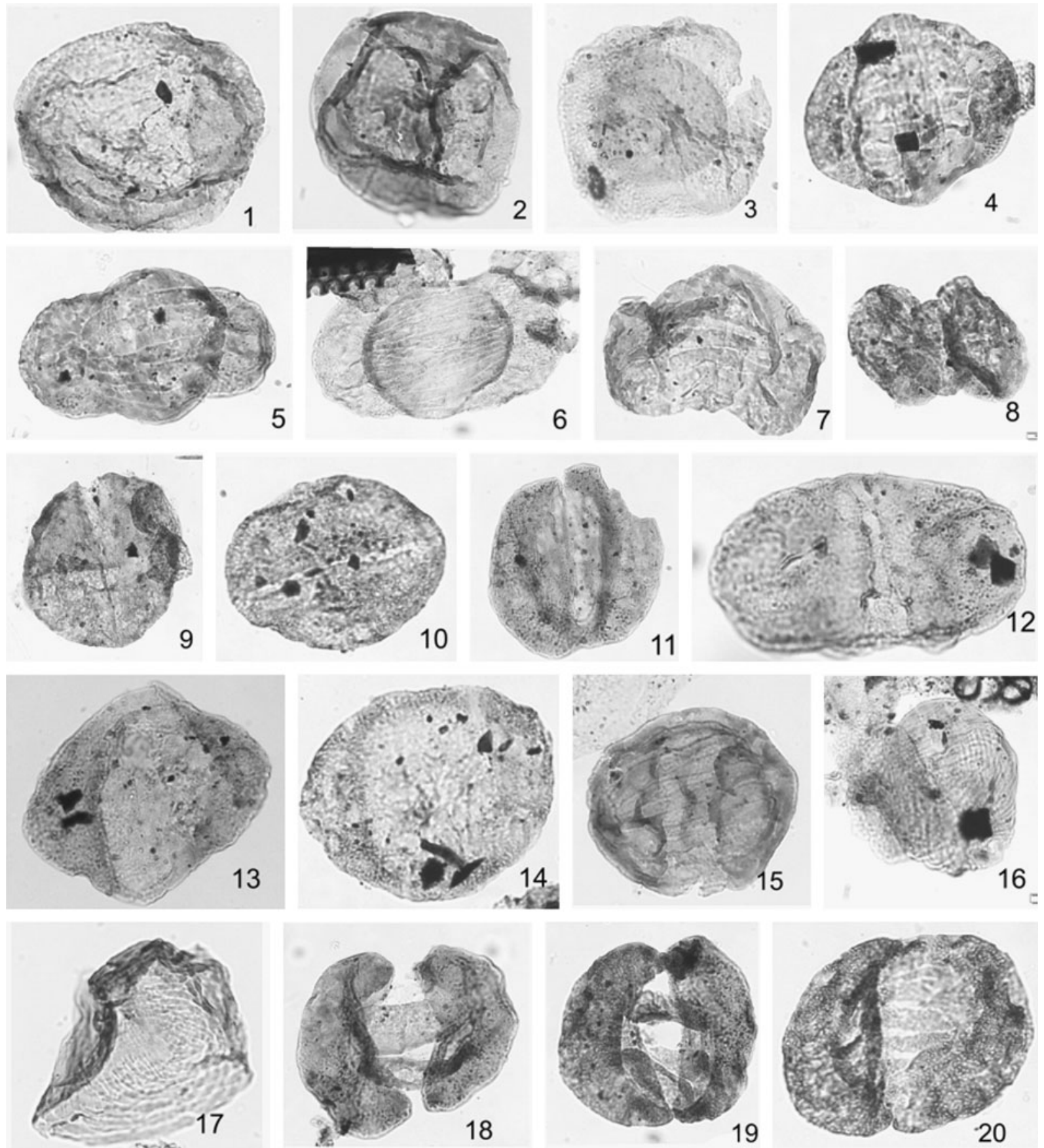

Plate 2. 1. Densipollenites invisus Bharadwaj and Salujha (1964); 2. Densipollenites magnicorpus Tiwari and Rana (1981); 3. Densipollenites indicus Bharadwaj (1962); 4. Distriatites bilateris Bharadwaj (1962); 5. Hamiapollenites sp.; 6. Striatopodocarpites magnificus Bharadwaj and Salujha (1964); 7. Striatites communis Bharadwaj and Salujha (1964); 8. Verticipollenites oblongus Bharadwaj (1962); 9. Scheuringipollenites tentulus (Tiwari) Tiwari (1973); 10. Faunipollenites prexiguus Bharadwaj and Salujha (1965); 11. Alisporites ovalis Kumar (1973); 12. Satsangisaccites nidpurensis Bharadwaj and Srivastava (1969); 13. Falcisporites minutosaccus Kumaran and Maheshwari (1980); 14. Alisporites damudicus Tiwari and Rana (1981); 15. Schzopollis distinctus Sinha (1972); 16. Weylandites minutus Bharadwaj and Srivastava (1969); 17. Weylandites irregularis Bharadwaj and Srivastava (1969); 18. Arcuatipollenites asansoliensis (Tiwari and Rana) Tiwari and Vijaya (1995); 19. Arcuatipollenites paliensis (Tiwari and Ram-Awatar) Tiwari and Vijaya (1995); 20. Arcuatipollenites pellucidus (Goubin) Tiwari and Vijaya (1995).

assemblage zone of Tiwari and Tripathi (1992), and dated as Early Triassic in age. The presence of acritarch is noteworthy. The nonproductive strata
(442.90-460.50 $\mathrm{m}$ in Borecore TROD-1), might represent the Raniganj-Panchet formational transition in this area. 
Table 5. List of the palynomorph taxa identified in present study, arranged under probable plant groups.

\begin{tabular}{|c|c|}
\hline Probable affinity & Palynotaxa \\
\hline Sphenopsida & $\begin{array}{l}\text { Calamospora Schopf, Wilson and Bentall (1944) } \\
\text { Calamospora sp. } \\
\text { Laevigatosporites Ibrahim (1933) } \\
\text { Laevigatosporites vulgaris Balme and Hennelly (1956) }\end{array}$ \\
\hline Lycopsida & $\begin{array}{l}\text { Indotriradites Tiwari (1964) } \\
\text { Indotriradites korbaensis Tiwari (1964) } \\
\text { Indotriradites sparsus Tiwari (1965) } \\
\text { Indotriradites surangei Tiwari (1965) } \\
\text { Dentatispora Tiwari (1964) } \\
\text { Dentatispora crassus Tiwari (1965) } \\
\text { Dentatispora lacunata Tiwari (1965) } \\
\text { Didecitriletes Venkatachala and Kar (1965) } \\
\text { Didecitriletes horridus Venkatachala and Kar (1965) } \\
\text { Densoisporites Weyland and Krieger emend. Dettman (1963) } \\
\text { Densoisporites sp. } \\
\text { Jayantisporites Lele and Makada (1972) } \\
\text { Jayantisporites sp. } \\
\text { Gondisporites Bharadwaj (1962) } \\
\text { Gondisporites reticulates Tiwari and Ram-Awtar (1989) } \\
\text { Gondisporites raniganjensis Bharadwaj (1962) } \\
\text { Lundbladispora Balme and Playford (1965) } \\
\text { Lundbladispora brevicula Balme (1963) } \\
\text { Lundbladispora raniganjensis Tiwari and Rana (1981) } \\
\text { Lundbladispora baculata Bharadwaj and Tiwari (1977) } \\
\text { Lundbladispora microconata Bharadwaj and Tiwari (1977) } \\
\text { Ringosporites Tiwari and Rana (1981) } \\
\text { Ringospotites fossulatus (Balme) Tiwari and Rana (1981) }\end{array}$ \\
\hline Filicopsida & $\begin{array}{l}\text { Apiculatisporis Potonie and Kremp (1956) } \\
\text { Apiculatisporis sp. } \\
\text { Brevitriletes Bharadwaj and Srivastava (1969) } \\
\text { Brevitriletes unicus Bharadwaj and Srivastava (1969) } \\
\text { Callumispora Bharadwaj and Srivastava emend. Tiwari et al (1989) } \\
\text { Callumispora gretensis (Balme and Hennelly) } \\
\text { Bharadwaj and Srivastava emend. Tiwari et al (1989) } \\
\text { Camptotriletes Naumova (1937) } \\
\text { Camptotriletes sp. } \\
\text { Cyclogranisporites Potonie and Kremp (1954) } \\
\text { Cyclogranisporites distinctus Kumaran and Maheshwari (1980) } \\
\text { Cyclogranisporites gondwanensis Bharadwaj and Salujha (1964) } \\
\text { Cyclogranisporites barakarensis Srivastva (1970) } \\
\text { Cyclogranisporites triletus Kar (1970) } \\
\text { Cyclobaculisporites Bharadwaj (1955) } \\
\text { Cyclobaculisporites bharadwajii Salujha (1965) } \\
\text { Cyclobaculisporites minutus Bharadwaj and Salujha (1964) } \\
\text { Didecitriletes Venkatachala and Kar (1965) } \\
\text { Didecitriletes horridus Venkatachala and Kar (1965) } \\
\text { Horriditriletes Bharadwaj (1962) } \\
\text { Horriditriletes curvibaculosus Bharadwaj and Salujha (1964) } \\
\text { Horriditriletes rampurensis Tiwari (1968) } \\
\text { Horriditriletes sp. } \\
\text { Indospora Bharadwaj (1962) } \\
\text { Lophotriletes (Naumova) Potonie and Kremp (1954) } \\
\text { Lophotriletes frequenssus Tiwari (1969) }\end{array}$ \\
\hline
\end{tabular}


Table 5. (Continued.)

Gymnosperms

Cycado-ginkgopsida

\section{Coniferopsida}

Monosaccate
Microbaculispora Bharadwaj (1962)

Microbaculispora barakarensis Tiwari (1965)

Microbaculispora indica (Tiwari) emend. Tiwari and Singh (1981)

Microbaculispora tentula Tiwari (1965)

Microfoveolatispora Bharadwaj (1962)

Microfoveolatispora bokaroensis Tiwari (1965)

Microfoveolatispora foveolata Tiwari (1965)

Osmundacidites Couper (1953)

Osmundacidites wellmanni Couper (1953)

Thymospora Wilson and Venkatachala (1963)

Thymospora thessnii Wilson and Venkatachala (1963)

Verrucosisporites Ibrahim emend. Smith (1971)

Verrucosisporites distinctus Tiwari (1965)

Verrucosisporites triassicus Bharadwaj and Tiwari (1977)

Ginkgocycadophytus Samoilovich (1953)

Ginkgocycadophytus novus Srivastava (1970)

Praecolpatites Bharadwaj and Srivastava (1969)

Praecolpatites sp.

Tiwariasporis Maheshwari and Kar (1967)

Tiwariasporis flavatus Maheshwari and Kar (1967)

Vittatina (Luber) Wilson (1962)

Vittatina sp.

Welwitschiapites Bolchowitina (1953)

Welwitschiapites tenuis Bharadwaj and Salujha (1964)

Weylandites Bharadwaj and Srivastava (1969)

Weylandites circularis Bharadwaj and Srivastava (1969)

Weylandites indicus Bharadwaj and Srivastava (1969)

Weylandites irregularis Bharadwaj and Srivastava (1969)

Weylandites minutes Bharadwaj and Srivastava (1969)

Barakarites Bharadwaj and Tiwari (1964)

Barakarites implicatus Tiwari (1965)

Caheniasaccites Lele and Makada (1972)

Caheniasaccites decorus Lele and Makada (1972)

Densipollenites Bharadwaj (1962)

Densipollenites densus Bharadwaj (1962)

Densipollenites indicus Bharadwaj (1962)

Densipollenites invisus Bharadwaj and Salujha (1964)

Densipollenites magnicorpus Tiwari and Rana (1981)

Distriamonosaccites Bharadwaj (1962)

Distriamonosaccites ovalis Bharadwaj and Salujha (1964)

Parasaccites Bharadwaj and Tiwari (1964)

Parasaccites bilateralis Tiwari (1965)

Parasaccites korbaensis Bharadwaj and Tiwari (1964)

Playfordiaspora Maheshwari and Banerji emend. Vijaya (1995)

Playfordiaspora cancellosa Maheshwari and Banerji emend. Vijaya (1995)

Plicatipollenites Lele (1964)

Plicatipollenites indicus Lele (1964)

Potonieisporites Maheshwari (1967)

Potonieisporites lelei Maheshwari (1967)

Striamonosaccites Bharadwaj (1962)

Striamonosaccites circularis Bharadwaj and Salujha (1964)

Nonstriate Bisaccate

Accintisporites sp.

Alisporites Daugherty emend. Jansonius (1971)

Alisporites damudicus Tiwari and Rana (1981) 
Table 5. (Continued.)

Alisporites ovalis Kumar (1973)

Brachysaccus Madler (1964)

Brachysaccus sp.

Caytonipollenites Couper (1953)

Caytonipollenites sp.

Cuneatisporites Leschik (1955)

Cuneatisporites sp.

Falcisporites Leschik emend. Klaus (1963)

Falcisporites minutosaccus Kumaran and Maheshwari (1980)

Krempipollenites Tiwari and Vijaya (1995)

Krempipollenites indicus Tiwari and Vijaya (1995)

Minutosaccus Madler (1964)

Minutosaccus sp.

Nidipolllenites Bharadwaj and Srivastava (1969)

Nidipolllenite sp. Bharadwaj and Srivastava (1969)

Platysaccus Naumova emend. Potonie and Klaus (1954)

Platysaccus sp.

Plicatisaccus Pautsch (1971)

Plicatisaccus sp.

Protoeusaccites Tiwari, Ram-Awatar and Vijaya (1995)

Protoeusaccites sp.

Sahnites Pant emend. Tiwari and Singh(1984)

Sahnites sp.

Satsangisaccites Bharadwaj and Srivastava (1969)

Satsangisaccites nidpurensis Bharadwaj and Srivastava (1969)

Scheuringipollenites Tiwari (1973)

Scheuringipollenites tentulus (Tiwari) Tiwari (1973)

Vestigisporites Balme and Hennelly emend. Tiwari and Singh (1984)

Striate Bisaccate

Circumstriatites Lele and Makada (1972)

Circumstriatites obscurus Lele and Makada (1972)

Crescentipollenites Bhardwaj, Tiwari and Kar (1974)

Crescentipollenites amplus (Balme and Hennely) Tiwari and Rana (1980)

Crescentipollenites sp.

Crescentipollenites fuscus (Baradwaj) Bhardwaj, Tiwari and Kar (1974)

Distriatites Bharadwaj (1962)

Distriatites bilateris Bharadwaj (1962)

Distriatites insolitus Bhardwaj and Salujha (1964)

Faunipollenites Bharadwaj (1962)

Faunipollenites varius Bharadwaj (1962)

Faunipollenites perexiguus Bharadwaj emend Tiwari et al (1989)

Primuspollenites Tiwari (1964)

Primuspollenites dicavus Tiwari (1965)

Rhizomaspora Wilson (1962)

Rhizomaspora indica Tiwari (1965)

Schizopollis Venkatachala and Kar (1964)

Schizopollis distinctus Sinha (1972)

Striasulcites Venkatachala and Kar (1968)

Striasulcites tectus Venkatachala and Kar (1968)

Striapollenites Bharadwaj (1962)

Striapollenites obliquus Bharadwaj and Salujha (1964)

Striatites Pant emend. Bharadwaj (1962)

Satriatites communis Bharadwaj and Salujha (1964)

Striatites gopalensis Srivastava (1970)

Striatites levistriatus Bharadwaj and Tiwari (1977)

Striatites ornatus Venkatachala and Kar (1968)

Striatites reticuloides Tiwari (1964) 
Table 5. (Continued.)

Taeniate Bisaccate

Striatites tectus Venkatachala and Kar (1968)

Striatites varius Kar (1968)

Striatopodocarpites Soritsch and Sedova emend. Bharadwaj (1962)

Striatopodocarpites ovatus (Maheshwari)

Bharadwaj and Dwivedi (1981)

Striatopodocarpites magnjficus Bharadwaj and Salujha (1964)

Verticipollenites Bharadwaj (1962)

Verticipollenites crassus Bharadwaj and Salujha (1964)

Verticipollenites debilis Venkatachala and Kar (1968)

Verticipollenites gibbosus Bharadwaj (1962)

Verticipollenites oblongus Bharadwaj (1962)

Arcuatipollenites Tiwari and Vijaya (1995)

Arcuatipollenites asansoliensis (Tiwari and Rana)

Tiwari and Vijaya (1995)

Arcuatipollenites diffusus (Tiwari and Rana)

Tiwari and Vijaya (1995)

Arcuatipollenites paliensis (Tiwari and Ram-Awtar)

Tiwari and Vijaya (1995)

Arcuatipollenites pellucidus (Goubin) Tiwari and Vijaya (1995)

Guttulapollenites Goubin (1965)

Guttulapollenites hannonicus Goubin (1965)

Trabeculosporites Trivedi and Misra emend.

Tiwari and Ram-Awtar (1992)

Trabeculosporites sp.

Algae and probable algae

Leiosphaeridia Eisanach emend. Downie and Sarjeant (1963)

Peltacystia Balme and Segroves (1966)

Quadrisporites Hennelly emend. Potonie (1961)

Tetraporina Naumova ex. Naumova emend. Kar and Bose (1976)

Tetraporina sp. Banerjee and D'Rozrio (1988)

Table 6. Palynodating of Borehole TRBD-2 (315.00-356.45 m depth), Tatapani-Ramkola Coalfield (Tiwari and Tripathi 1992, Vijaya et al 2001).

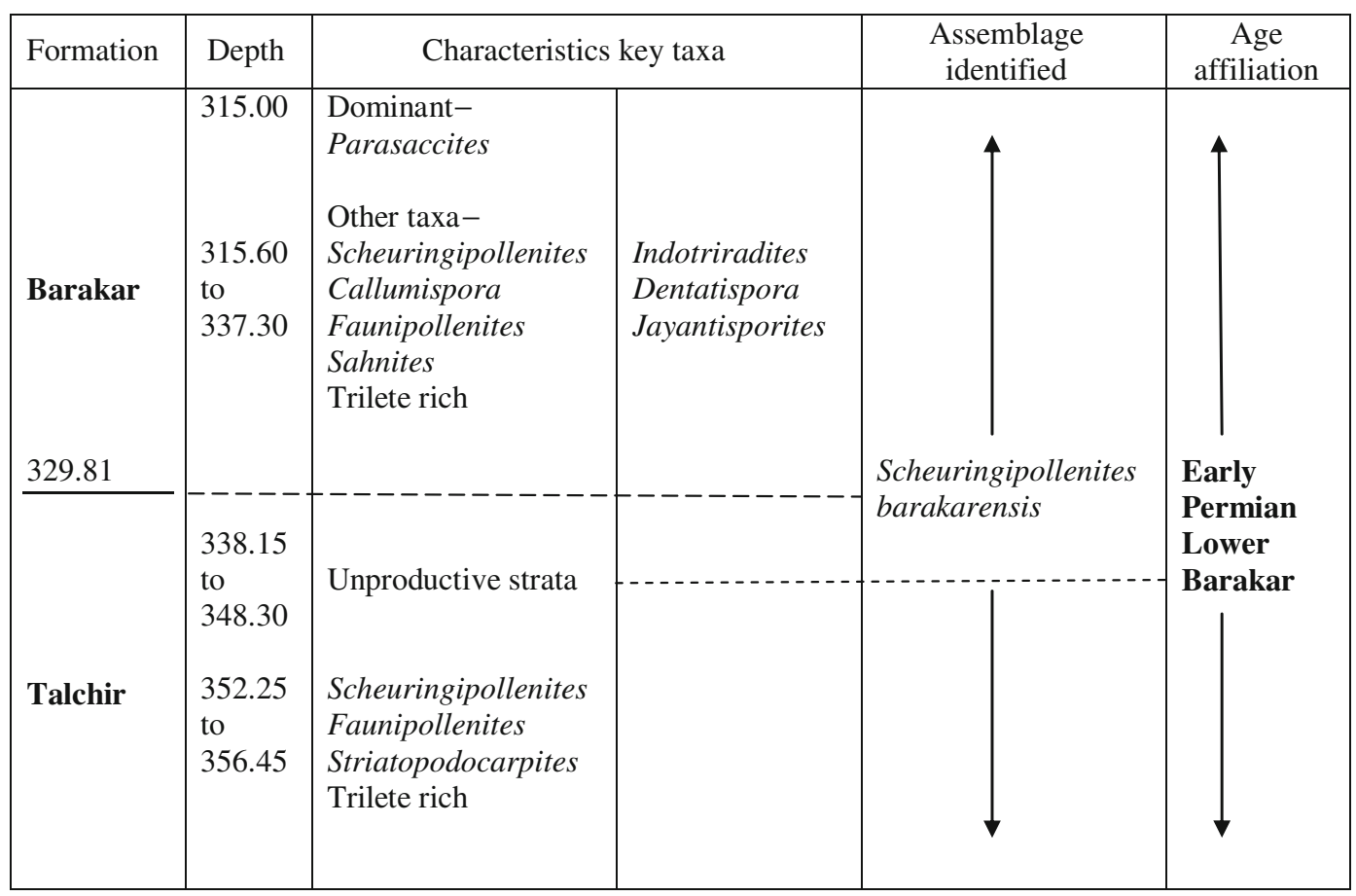


Table 7. Palynodating in Borehole TRBD-3 (19.00-515.20 m depth) Tatapani-Ramkola Coalfield (Tiwari and Tripathi 1992, Vijaya et al 2001).

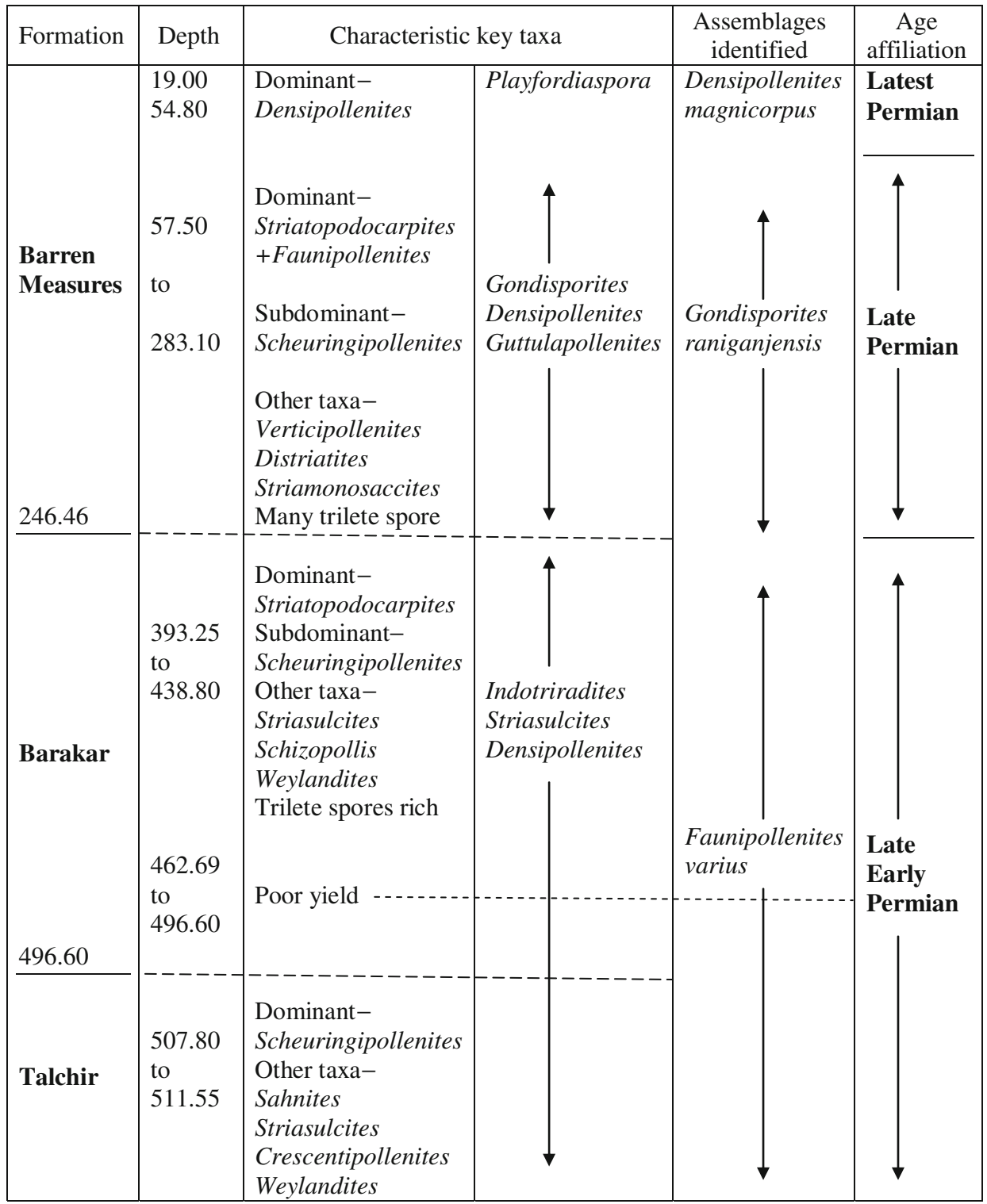

\section{Discussion}

Here, in Tatapani-Ramkola Coalfield, the lithological units are typified with characteristic lithofacies. The argillaceous component includes clay, carbonaceous shales, black shales, silty shales, laminated shales along with micaceous content. The arenaceous component is mainly medium- to fine-grained sandstone. Lithologically, the strata are delineated into Talchir, Barakar and Barren Measures formations. The palynological findings differ at places in the three borecores - TRBD-2, TRBD-3 and TROD-1, which are located in the nearby blocks (figures 1-3), needed to be defined in timespan. The strata lithologically identified as of Talchir Formation in borecores TRBD-2 and TRBD-3 is equated with the Lower Barakar
Formation of Damodar Basin (tables 6 and 7). Palynologically the strata pertaining to Barakar Formation in borecores TRBD-2, TRBD-3 conform the lithological demarcation (tables 6 and 7 ). However, in the Borecore TROD-1, the strata lithologically identified as Barakar Formation is palynologically dated as Late Permian and equated with the Raniganj Formation of Damodar Basin (table 8). In the up-section, the changing patterns observed in the palynoassemblages in the Barren Measures Formation in borecores TRBD-3 and TROD-1 have led in the identification of strata equivalent to the Raniganj and Lower Panchet formations of that in the Damodar Basin (figure 4).

The yield of spore-pollen, other plant tissues and organic matter is intermittently rare to rich. 
Table 8. Palynodating in Borehole TROD-1 (5.66-645.15 m depth), Tatapani-Ramkola Coalfield (Tiwari and Tripathi 1992, Vijaya et al 2001).

\begin{tabular}{|c|c|c|c|c|c|}
\hline Formation & Depth & Characteristic & key taxa & $\begin{array}{c}\text { Assemblage } \\
\text { identified }\end{array}$ & $\begin{array}{c}\text { Age } \\
\text { affiliation }\end{array}$ \\
\hline $\begin{array}{l}\text { Barren } \\
\text { Measures }\end{array}$ & $\begin{array}{l}460.50 \\
\text { to } \\
645.15\end{array}$ & $\begin{array}{l}\text {----------- } \\
\text { Dominant- } \\
\text { Striatopodocarpites } \\
\text { Other taxa- } \\
\text { Densipollenites } \\
\text { Guttulapollenites } \\
\text { Crescentipollenites } \\
\text { Distriatites } \\
\text { Accintisporites } \\
\text { Barakarites } \\
\text { Varied trilete but } \\
\text { low frequency }\end{array}$ & $\begin{array}{l}\text { Proliferation of } \\
\text { Playfordiaspora } \\
\text { at } 65.00 \mathrm{~m} \\
\text { First occurrences } \\
\text { of Plicatisaccus } \\
\text { Brachysaccus } \\
\text { at } 409.80 \mathrm{~m} \text {, and } \\
\text { Minutosaccus } \\
\text { at } 442.90 \mathrm{~m} \\
\end{array}$ & $\begin{array}{l}\text { Krempipollenites } \\
\text { indicus }\end{array}$ & $\begin{array}{l}\mid \\
\text { Early } \\
\text { Triassic } \\
\quad \mid\end{array}$ \\
\hline
\end{tabular}

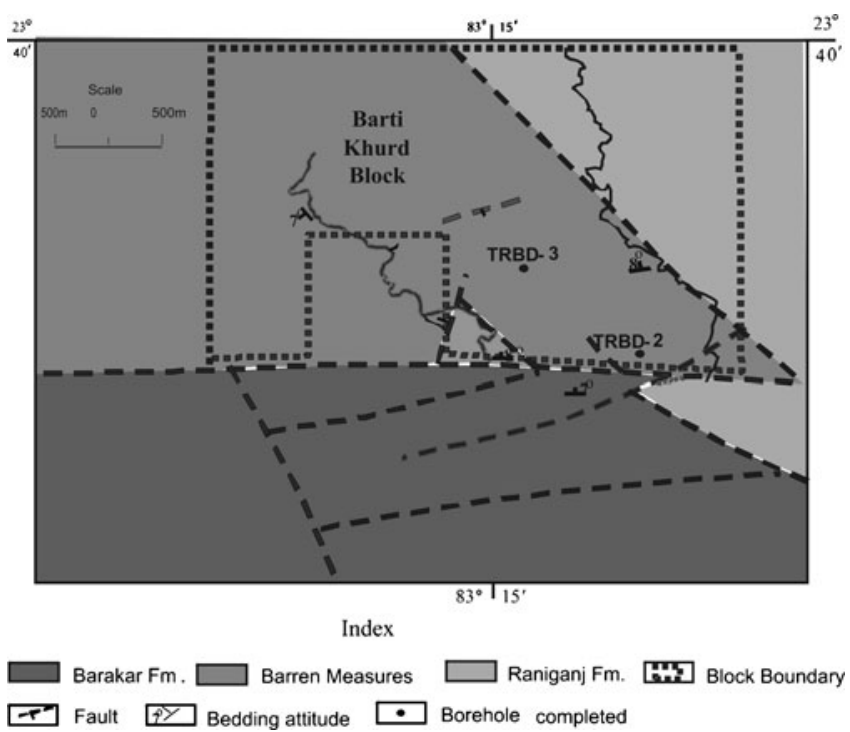

Figure 2. Geological map of Bartikhurd block, TatapaniRamkola Coalfield, Surguja district, Chhattisgarh.

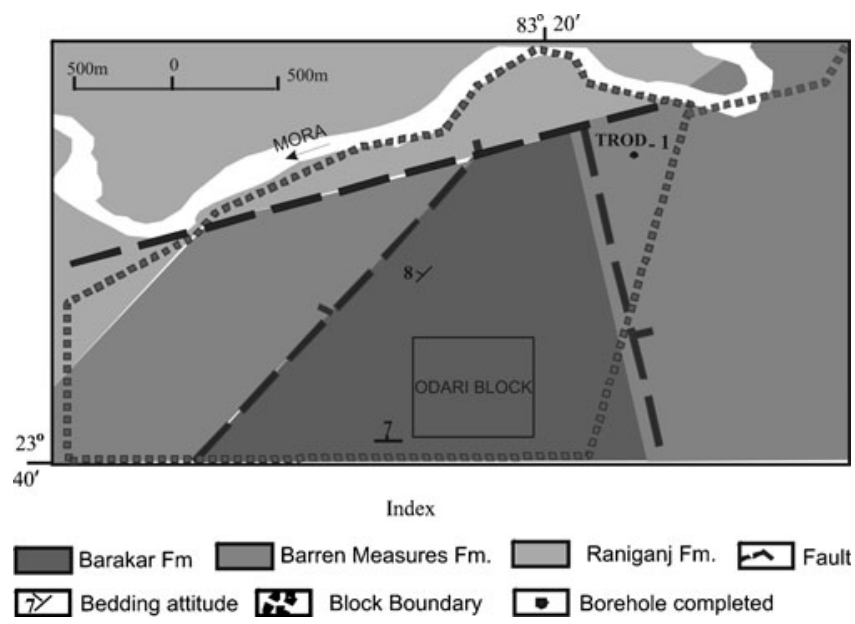

Figure 3. Geological map of Odari block, TatapaniRamkola Coalfield, Surguja district, Chhattisgarh. 


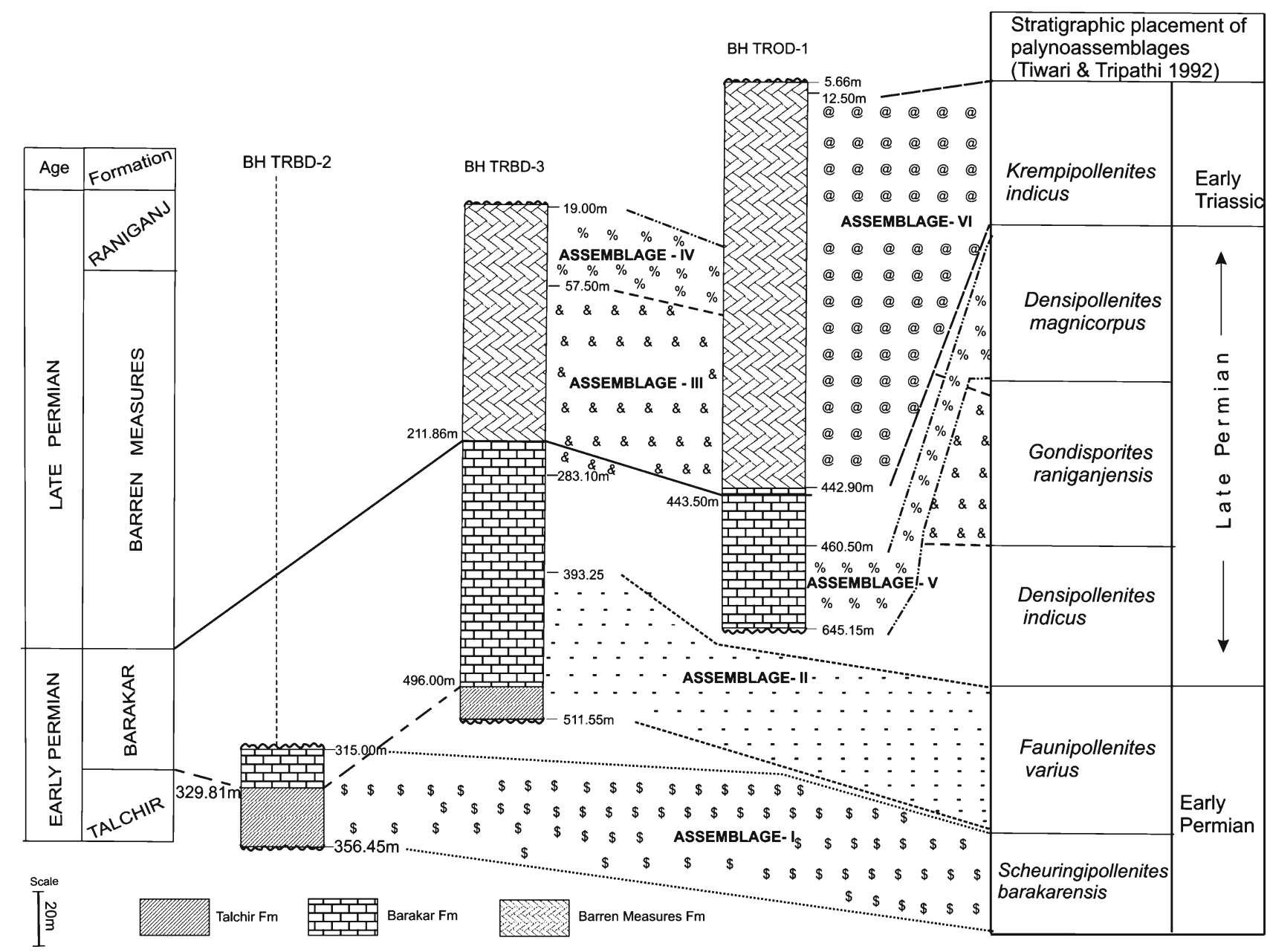

Figure 4. Biostratigraphic status of the palynoassemblages identified in the Talchir, Barakar and Barren Measures formations from the boreholes - TRBD-2, TRBD-3 in Bartikhurd block, and TROD-1 in Odari block, Tatapani-Ramkola Coalfield, Chhattisgarh.

The preservation in general is fair-to-good, but at various depths it is poor (tables 2-4). This observation that the energy was low to medium during the deposition of these sediments which corresponds with the lithofacies, more of argellacious component than arenaceous in the strata studied here.

\section{Conclusions}

The palynological studies done in approximately $1174.00 \mathrm{~m}$ thick Gondwana strata intersected through Barren Measures, Barakar and Talchir formations in the three borecores in TatapaniRamkola Coalfield, infers (figure 4):

- The strata lithologically demarcated as Talchir Formation (329.81-353.45 m, Borecore TRBD2 ), is here palynologically equated with the basal part of Lower Barakar Formation and dated Early Permian.

- The Barakar and Talchir formational contact lies at $329.81 \mathrm{~m}$, and the strata $(352.25-356.45 \mathrm{~m})$ overlying to this contains Scheuringipollenites barakarensis Palynozone equitable with the Lower Barakar Formation.

- However, strata in between 338.15 and $348.30 \mathrm{~m}$ is unproductive.

- In approximately $493.00 \mathrm{~m}$ thick strata comprising Barren Measures and Barakar formations in Borecore TRBD-3, only $72.00 \mathrm{~m}$ of the Barakar Formation has yielded the Faunipollenites varius Palynozone, which conforms lithological delimitation that is Barakar Formation.

- Other two assemblages recovered in the Barren Measures Formation (57.50-283.10 $\mathrm{m}$ and 19.00-57.50 m in Borecore TRBD-3) compare with the Late Permian palynoflora known from 
Raniganj Formation (figure 4). This implies a younger status to the studied strata.

- Palynological dating of the 460.50-645.15 m depth in Borecore TROD-1, the Barakar Formation contains Densipollenites magnicorpus Palynozone that equates this part with the upper part of Raniganj Formation, Late Permian.

- Strata identified as the Barren Measures (12.50$442.90 \mathrm{~m}$ depth in Borecore TROD-1) has yielded Krempipollenites indicus Palynozone, which suggests an affiliation with Lower Panchet Formation of Early Triassic in age.

- Here, the non-productive strata (442.90$460.50 \mathrm{~m}$ in Borecore TROD-1), might represent the Raniganj-Panchet formational transition (P/Tr transition).

In Tatapani-Ramkola Coalfield, the strata of Talchir Formation are palynologically equated with the Barakar Formation Early Permian. While in the Barakar and Barren Measures formations, existence of the Raniganj Formation Late Permian is identified, of that in Damodar Basin. In Barren Measures Formation, it also encompasses a part deposited during the Early Triassic time.

\section{Acknowledgements}

The authors (A Tripathi, Vijaya and S Murthy) express their thanks to Director, BSIP, Lucknow for the kind permission to publish this work. They extend their sincere thanks to the Dy. DG and officers of the Coal Wing Division, Geological Survey of India, Kolkata, for providing borecore samples for palynological study. This work has been carried out under MOU between BSIP and Coal Wing Division, Geological Survey of India, Kolkata.

\section{References}

Bose M N, Banerji J and Maithy P K 1977 Some fossil plant remains from Ramkola-Tatapani Coalfields, Madhya Pradesh; Palaeobotanist 24 108-117.

Raja Rao C S 1983 Coal resources of Madhya Pradesh and Jammu \& Kashmir; Bull. Geol. Surv. India Series A, No. 45, Coalfields of India III, pp. 1-204.

Srivastava S C and Ratan Kar 2001 Palynological dating of some Permian outcrops from Iria valley, TatapaniRamkola Coalfield, MP, India; In: Proceeding of National Seminar on Recent Advance in Geology of coal and lignite basins of India, Calcutta, Geol. Surv. India Spec. Publ. 54 97-102.

Srivastava S C, Prakash A and Ratan Kar 1997 Palynology Permian-Triassic sequence in Ira nala, TatapanRamkola, Coalfield, India; Palaeobotanist 46(1, 2) 75-80.

Tiwari R S and Tripathi A 1992 Marker assemblage zones of spore and pollen species through Gondwana Paleozoic and Mesozoic sequence in India; Palaeobotanist 40 $194-236$.

Vijaya, Tripathi A and Ram-Awatar 2001 Vertical distribution of spore and pollen index species in the Permian sequence on Peninsular India; In: Contribution to geology and paleontology of Gondwana (ed.) R H Weiss, Germany, pp. $475-495$. 